\title{
Correlation between the global occurrences of ionospheric irregularities and deep atmospheric convective clouds in the intertropical convergence zone (ITCZ)
}

\author{
Shin-Yi Su ${ }^{1,2^{*}}$, Chung Lung Wü and Chao Han Liu ${ }^{3}$
}

\begin{abstract}
To study the seeding mechanism of ionospheric irregularity occurrences, a correlation study has been carried out between the global monthly/latitudinal $(\mathrm{m} / \mathrm{l})$ distributions of irregularity occurrences and the deep atmospheric convective clouds in the intertropical convergence zone (ITCZ) indicated by the outgoing longwave radiation (OLR) measurements. Seven longitude sectors - the African, Indian, West Pacific, Central Pacific, East Pacific, South American, and Atlantic sectors - are selected to study the correlations between the two distributions. The results indicate that good correlations exist only in the South American sector and to some extent in the African sector. For the other five sectors, no correlations are found in the $\mathrm{m} / \mathrm{l}$ distributions between the irregularities and OLRs. This implies that the gravity wave induced in the ITCZ cannot be the sole seeding agent for the Rayleigh-Taylor (RT) instability in the global irregularity occurrences every season. We suspect that the post-sunset ionospheric electrodynamic perturbations could be the prevailing seeds for the RT instability globally year long. Together with the favorable post-sunset ionospheric condition, the global $\mathrm{m} / \mathrm{l}$ distributions of irregularity occurrences could be adequately explained.
\end{abstract}

Keywords: Ionospheric density irregularity; Gravity wave; OLR; ITCZ

\section{Findings}

Introduction

The post-sunset equatorial ionospheric density irregularity occurrences, or the so-called equatorial spread $\mathrm{F}$ (ESF) events, have been studied extensively with in situ rocket and satellite measurements; from ground experiments with radars, scintillation measurements, and radio sounders; and with computer simulations (see, e.g., Woodman and LaHoz 1976; McClure et al. 1977; Kelley and McClure 1981; Ossakow 1981; Keskinen et al. 1981; Kelley et al. 1982; Hysell and Burcham 1998; Huba et al. 2008; Retterer 2010). Many experimental studies have resulted in the well-known global seasonal/longitudinal $(\mathrm{s} / \mathrm{l})$ distributions of ionospheric irregularity occurrence

\footnotetext{
* Correspondence: sysu@jupiter.ss.ncu.edu.tw

${ }^{1}$ Center for Space and Remote Sensing Research, National Central University, 300 Chung-Da Road, Chung-Li 320, Taiwan

${ }^{2}$ Institute of Space Science, National Central University, 300 Chung-Da Road, Chung-Li 320, Taiwan

Full list of author information is available at the end of the article
}

rates (Aarons 1982, 1993; Maruyama and Maturra 1984; Tsunoda 1985, 2010a, c; Watanabe and Oya 1986; Kil and Heelis 1998; McClure et al. 1998; Huang et al. 2002; Burke et al. 2004, Hei et al. 2005; Su et al. 2006; Gentile et al. 2006; Stolle et al. 2006; Park et al. 2013).

The cause of density irregularity occurrences seems to originate from a hierarchy of multi-step non-local plasma process involving an interchange instability that includes collisional and collisionless Rayleigh-Taylor (RT) and $\vec{E} \times \vec{B}$ instabilities, and drift waves driven by coupled electrodynamics and neutral atmosphere processes (Hanson et al. 1973; Harerendel 1973; Ossakow 1981; Keskinen et al. 1981; Sultan 1996). The growth of a linearized RT instability depends on the existence of a steep, upward plasma density gradient in the bottomside ionosphere after sunset. When the sunset terminator is closely aligned with the equatorial magnetic flux tube, a large longitudinal conductivity gradient will result. This then induces a large pre-reversal enhancement of vertical drift velocity that raises the post-sunset ionosphere to 
become susceptible to the RT instability (Abdu et al. 1982; Mendillo et al. 1992; Fejer et al. 1999). Tsunoda (1985) has indeed demonstrated that the seasonal variation in the alignment of the sunset terminator with the geomagnetic field line at the dip equator can explain the observed s/l distributions of scintillations with high occurrences at longitudes of positive (negative) magnetic declination during June (December) solstice and at longitudes of null magnetic declinations in the equinoxes. Thus, the observed s/l distributions of irregularity occurrences exhibit a high occurrence of irregularities during a season at a longitude sector for a so-called 'ESF season' versus 'non-ESF season' in a different season of fewer irregularity occurrences.

Since the seeding mechanism is always needed for the RT instability, the global s/l distributions of the seeding agent should have a good correlation with the global s/l distributions of irregularity occurrences. Among the perturbation seeds studied in recent years, the atmospheric gravity wave has been considered as the most likely seed for the RT instability (Rottger 1981; Hysell et al. 1990; Huang et al. 1993; Huang and Kelley 1996; McClure et al. 1998; Tsunoda 2010a, c).

As the atmospheric gravity waves will appear during a severe weather, we will use the space-observed deep atmospheric convective clouds in the intertropical convergence zone (ITCZ) as the proxy of gravity wave occurrences in the following study. Correlation between the irregularity occurrences and the ITCZ cloud distributions was first suggested in the report of McClure et al. (1998) and then extensively studied by Tsunoda (2010a, c) who demonstrated that the atmospheric gravity waves generated in the ITCZ can serve as seeds of the RT instabilities during solstices at some longitude sectors. Here, we will carry out a similar study of correlation using a better temporal/spatial resolution in the monthly/ latitudinal $(\mathrm{m} / \mathrm{l})$ distributions of density irregularity occurrences obtained by ROCSAT and the deep atmospheric convective clouds observed with the outgoing longwave radiation (OLR) measurements in the ITCZ. The monthly variation in the latitudinal migration of the cloud system and the irregularity occurrences can be studied for a better topographic correlation, and the linear regression analysis between the two variables at a longitude sector year long will confirm if the atmospheric gravity wave can indeed seed the RT instability globally every season.

\section{Data analyses}

\section{ROCSAT observations}

ROCSAT orbited at a $600-\mathrm{km}$ altitude with a $35^{\circ}$ inclination from 1999 to 2004. The observed ionospheric density irregularities have been studied and published in a report by $\mathrm{Su}$ et al. (2006). For the current study, the irregularity occurrences within $\pm 25^{\circ}$ in the geographic latitude are used to coincide with the cloud distributions observed within $\pm 25^{\circ}$ in the geographic latitudes for the ITCZ. The global s/l distributions of irregularity occurrences are shown in the upper panels for each season in Figure 1. The longitudinal and latitudinal resolution is $1^{\circ}$ by $1^{\circ}$. A white dotted line is drawn to represent the dip equator in each panel to emphasize the fact that the equatorial irregularity occurs around the dip equator. We notice that the occurrence frequency (indicated by the color coding) varies from one longitude to the next as season changes.

\section{Cloud climatology in the ITCZ}

Observations of highly reflective clouds (HRC) from space have been used to represent the tropical climatology in the ITCZ in the past (Waliser et al. 1993). Recently, the OLR observation has been used to measure the deep atmospheric convection in the ITCZ (Waliser and Gautier 1993; Gu and Zhang 2002). To coincide with the mission period of ROCSAT, we use the NOAA 14 and 16 observed OLR distributions during the same time period for the current study (http://www.esrl.noaa.gov/psd/data/gridded/ data.interp_OLR.html).

The global s/l distributions of OLR observations are shown in the lower panel for each season in Figure 1. The resolution is $2.5^{\circ}$ by $2.5^{\circ}$ in the geographic bin. The unit of OLR occurrence is day/month, and the frequency of occurrence is indicated by the color coding. The occurrence of OLR is defined as the OLR measurement below $200 \mathrm{~W} / \mathrm{m}^{2}$ in each bin per day. When the OLR measurement is below $205 \mathrm{~W} / \mathrm{m}^{2}$, a deep atmospheric convection will occur (Gu and Zhang 2002). A gravity wave is then assumed to exist in the deep convective clouds. The frequency of OLR occurrences represents the frequency of gravity wave occurrences. It should be noted that weak gravity waves could occur in the OLR measurements above $200 \mathrm{~W} / \mathrm{m}^{2}$. However, for the climatological study of correlation between irregularities and gravity waves, using a well-defined threshold to assure for the gravity wave occurrences in the OLRs will result in a clear conclusion.

A white dotted line is drawn along the geographic equator in the plot of OLR observations to highlight the seasonal variation in the latitudinal migration of OLR occurrences between hemispheres. This is to contrast the irregularity distribution seen in the upper panel for the same season.

\section{Longitudinal occurrence distributions between irregularities and OLRs}

There are many vertical lines drawn in Figure 1, which divide the global longitudes into seven sectors for the study of correlation between the irregularity occurrences and OLR observations. The seven longitude sectors are listed in Table 1. These seven sectors were selected by 


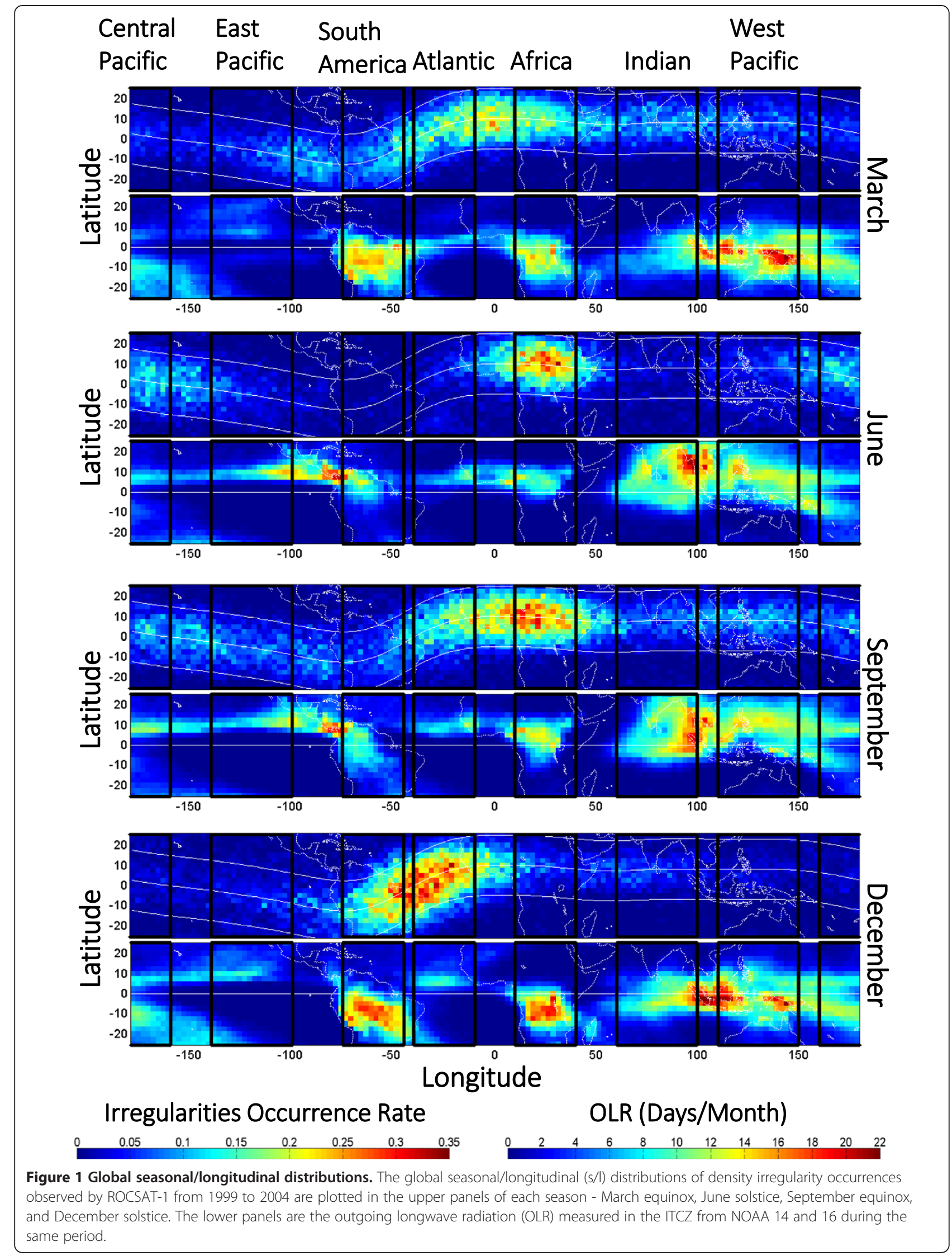


Table 1 Longitude ranges and magnetic declinations in the seven longitude sectors

\begin{tabular}{lcc}
\hline Region & Longitude range & Magnetic declination \\
\hline Africa & $10^{\circ}$ to $40^{\circ} \mathrm{E}$ & Approximately $0^{\circ}$ \\
Indian & $60^{\circ}$ to $100^{\circ} \mathrm{E}$ & Approximately $0^{\circ}$ \\
West Pacific & $110^{\circ}$ to $150^{\circ} \mathrm{E}$ & Approximately $0^{\circ}$ \\
Central Pacific & $160^{\circ} \mathrm{E}$ to $160^{\circ} \mathrm{W}$ & Approximately $+10^{\circ}$ \\
East Pacific & $100^{\circ}$ to $140^{\circ} \mathrm{W}$ & Approximately $+10^{\circ}$ \\
South America & $45^{\circ}$ to $75^{\circ} \mathrm{W}$ & Approximately $-20^{\circ}$ \\
Atlantic & $10^{\circ}$ to $40^{\circ} \mathrm{W}$ & Approximately $-15^{\circ}$ \\
\hline
\end{tabular}

Waliser and Gautier (1993) to study the deep convection in the cloud systems between ocean and land. Tsunoda $(2010 \mathrm{a}, \mathrm{c})$ also studied the seeding mechanism of ESF events during the solstices in some of these sectors. Different magnetic declinations at different longitude sectors seen in the table will manifest different characteristics of irregularity occurrences to compare with the OLR observations.
From the visual inspection of the s/l distributions between the irregularity occurrences and the OLR observations for each season in Figure 1, we notice that the gross feature of the $\mathrm{s} / \mathrm{l}$ distributions between the two occurrence patterns is completely different from each other topographically. Basically, high occurrences of irregularities are concentrated from $-60^{\circ}$ to $+50^{\circ}$ in longitude. On the other hand, most of the high occurrences of OLRs are spread in the South American, African, Indian, and West Pacific sectors. There seems to be topographic overlap of high occurrence patterns in the December solstice and in the equinoxes only in the South American and African sectors, respectively.

For a better comparison of the two distributions shown in Figure 1, we plot in Figure 2 the $\mathrm{m} / \mathrm{l}$ distributions of irregularities and OLRs for each longitude sector. These plots will highlight the latitudinal variations of the two occurrence distributions in different months (seasons).

We first notice in Figure 2 that the general pattern of the monthly variation of OLRs indicates an upside down

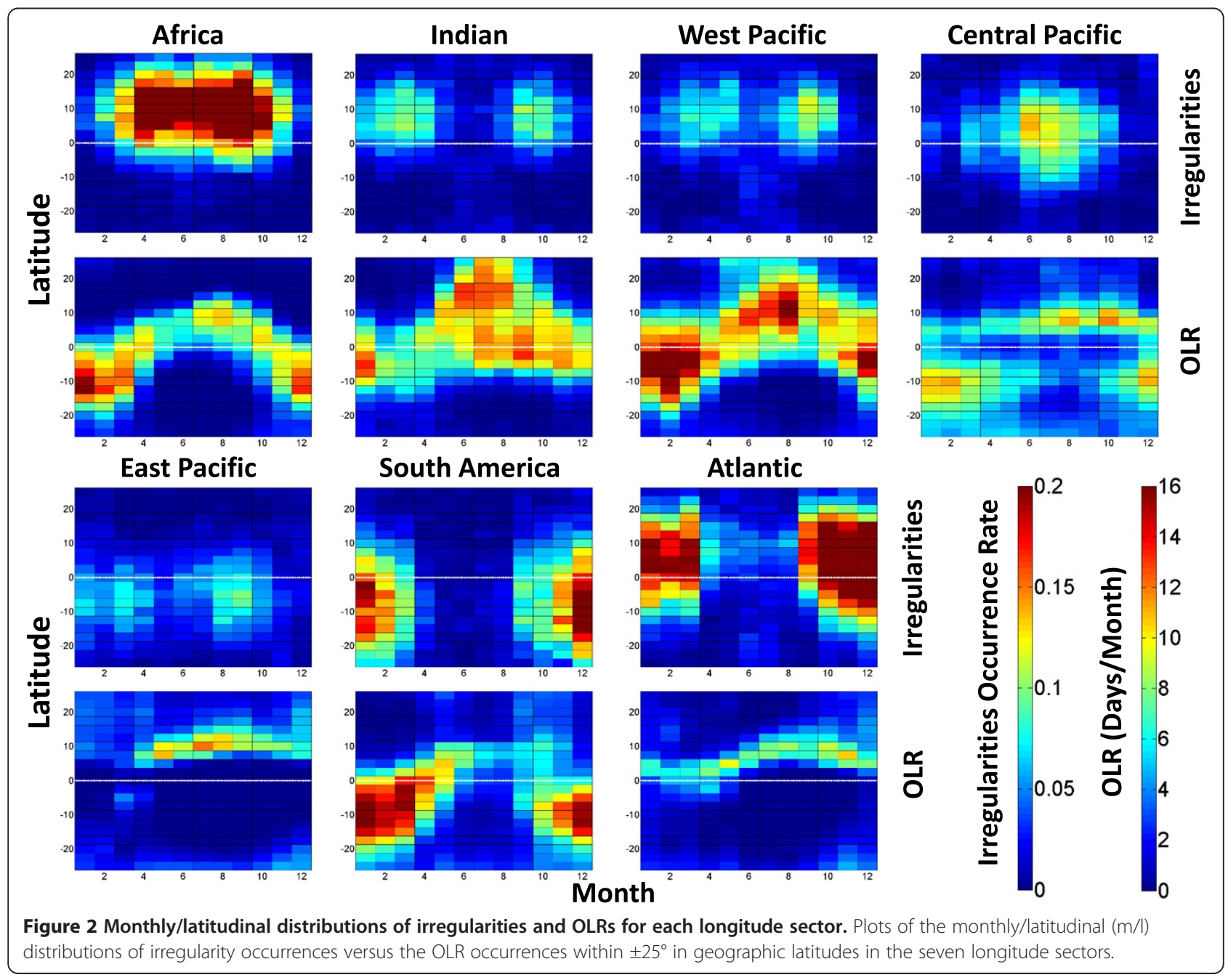


V shape (sometimes broken) with the observed OLRs moving to the northern hemisphere around the June solstice and to the southern hemisphere around the December solstice caused by the seasonal variation of solar radiation effect. However, there are two sectors, the East Pacific and Atlantic sectors, where the OLRs stay in the northern hemisphere even in the December solstice. This is caused by the additional effect of sea surface temperature. In contrast, the irregularity occurrences remain around the dip equator with no latitudinal migration but exhibit the occurrence variations between the ESF season and non-ESF season. Thus, in the seven longitude sectors, similar $\mathrm{m} / \mathrm{l}$ distributions between the irregularities and OLRs are noticed only in the South American sector. This is because the dip equator is located in the southern hemisphere in the South American sector where the ESF season appears in the December solstice due to negative magnetic declination. As the observed OLR moves to the southern hemisphere during the December solstice, the two occurrence distributions coincide with each other. This observation has been noted by Tsunoda (2010a,c).

On the other hand, no correlation exists between the irregularities and OLRs during the June solstice in the Central Pacific sector where the magnetic declination is positive. This is because high irregularity occurrences appear during the June solstice in the northern hemisphere in this sector, but the northward migration of OLRs is delayed in this oceanic region due to warmer sea surface temperature so that high occurrences of OLRs shift to the September equinox. The magnetic declination in the East Pacific sector is also positive, but the dip equator cuts across the geographic equator to move to the southern hemisphere so that high occurrences of irregularities shift to the September equinox and appear in the southern hemisphere, whereas the OLRs still stay in the northern hemisphere and fail to correlate with the irregularity occurrences. Similar observations can be applied to the other four sectors where the seasonal migrations of OLR occurrences between the two hemispheres do not correlate with the irregularity occurrences that stay around the dip equator.

\section{Monthly/latitudinal distributions}

For the gravity wave to seed the RT instability, it should appear close to the location where the RT instability is initiated at the dip equator (Tsunoda 2010c). However, when the generated irregularity rises with the flux tube, it can be observed at different latitudes depending on the location of the flux tube traversed by ROCSAT. Therefore, we study the linear regression between the monthly total irregularity occurrence rates and the number of OLR observations between $\pm 15^{\circ}$ of the dip equator. This can also account for the possible tilted upward propagating gravity waves which originated far away from the dip equator. The results are shown in Figure 3.

Here, we have separated the plots in the figure into two parts in four rows. Plots in the first and the third row are the monthly occurrences of irregularities and OLRs. The bar chart shows the number of days in a month for the OLR occurrence, and the red dotted line shows the irregularity occurrence rate. For the plots in the second and the fourth rows, linear regression of the monthly occurrences between the irregularities and OLRs in a longitude sector is shown. The linear regression analyses indicate that the African, South American, and Atlantic sectors have positive correlations between the irregularities and OLRs, while the Indian, West Pacific, Central Pacific, and East Pacific sectors have a negative correlation.

From the results of the linear regression together with the graphic comparison between the monthly occurrence variations of irregularities and OLRs in the upper panels for each longitude sector shown in Figure 3, we will state that the irregularity and OLR occurrences in the South American sector indicates a very good correlation. The number of OLR occurrences that is twice as high as the number of irregularity occurrences can provide a constant seeding activity. In addition, the irregularity and OLR occurrences in the African sector seem to indicate a good correlation because the latitude range has been narrowed to around the dip equator so that a large number of OLRs that appear in the southern hemisphere during the December solstice are excluded ( $c f$. Figure 2). However, the occurrence rate of OLRs in days/month is about half of the occurrence rate of irregularities from April to September. On the other hand, the positive correlation that appears in the Atlantic sector should not indicate a good correlation because the irregularity occurrence rate varies drastically from $4 \%$ to $20 \%$ in June to December solstice, while the OLR occurrence rate stays flat at about 3 days/month (10\%) year long. No correlation conclusion is also drawn for the East Pacific sector where a negative regression is noticed and the OLR occurrences are low to compare with high irregularity occurrences from June to October. Similarly, no correlation is concluded for the Indian, West Pacific, and Central Pacific sectors, because the correlations are negative between the irregularities and OLRs and the OLRs are more abundant than the irregularities.

Therefore, the quantitative study from the linear regression analysis of the $\mathrm{m} / \mathrm{l}$ distributions of irregularities and OLRs indicates that the two distributions have good correlations year long only in the South American and African sectors. No correlation is found for the other five longitude sectors. 


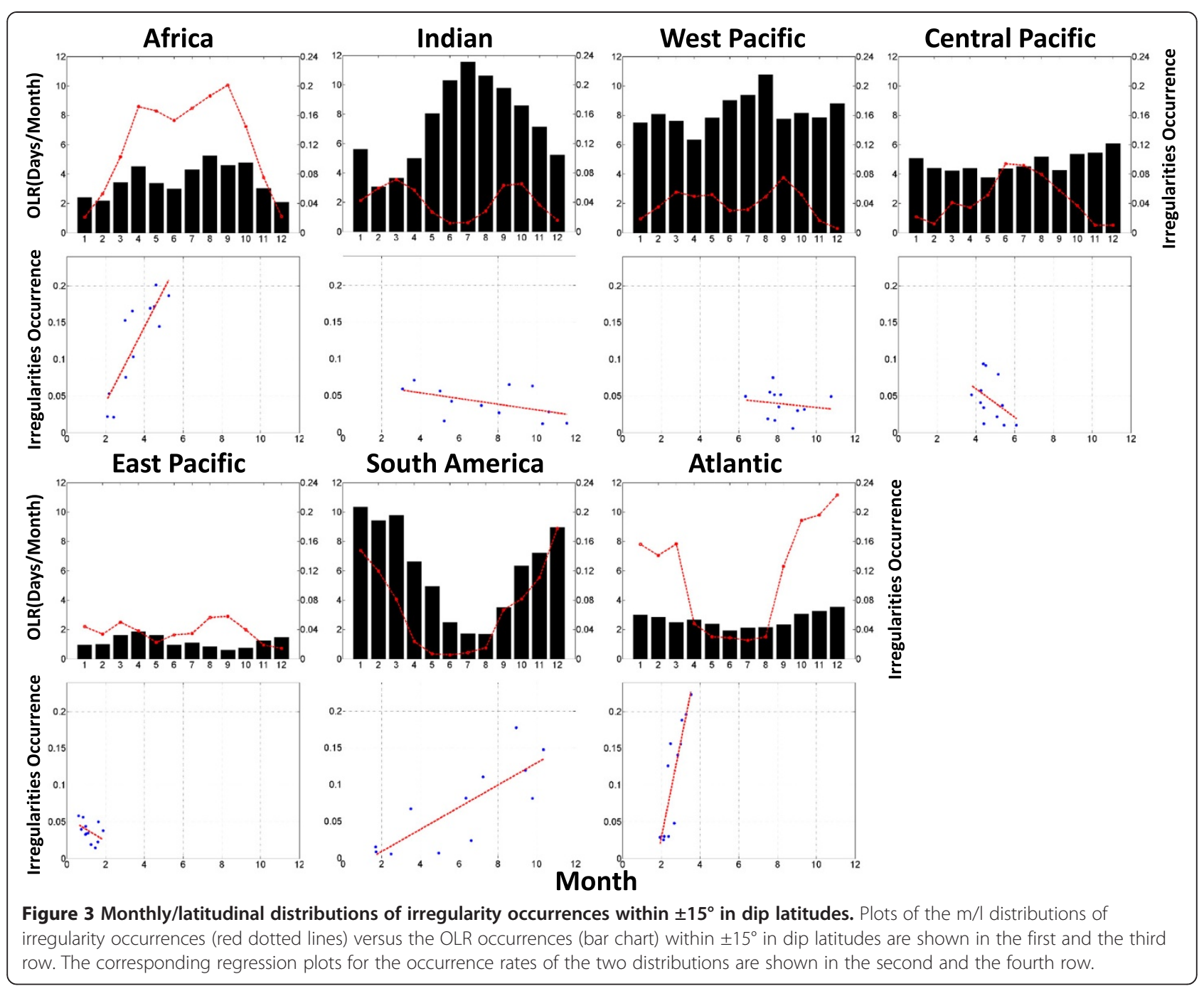

\section{Discussions and conclusions}

Correlation studies carried out between the $\mathrm{m} / \mathrm{l}$ distributions of density irregularities and the $\mathrm{m} / \mathrm{l}$ distributions of OLR observations in the ITCZ as the proxy of gravity wave occurrences at seven longitude sectors indicate that good correlations between the irregularities and OLRs only exist in the South American sector and to some extent in the African sector. For the other five longitude sectors, the monthly occurrence distributions between the irregularities and OLRs do not correlate with each other topographically or in the linear regression analysis. The irregularity occurrences are either much higher than the OLR occurrences in some months as in the Atlantic sector or, the other way around, much lower than the OLR occurrences as in the Indian, West Pacific, and Central Pacific sectors. When the OLR occurrences are smaller than the occurrences of irregularities, it implies that the gravity wave cannot be the only seed for the RT instability. On the other hand, when many OLRs result in a few irregularities, the effectiveness of gravity wave seeding is in doubt. This could be due to the fact that the induced gravity wave generated in the ITCZ is blocked by the wind filtering effect around the mesospheric height in the upward propagation from the troposphere to the ionosphere (Mukherjee et al. 2010) or by the polarization factor of the gravity wave that fails to trigger the irregularity occurrences (Tsunoda 2010b). Therefore, the current study concludes that the gravity wave induced in the convective clouds in the OLRs of ITCZ cannot be the sole seeding agent for the RT instability to produce irregularities year long at many longitude sectors.

Our conclusion may seem different from what has been published by Tsunoda (2010a,c) who concluded that the evidence of gravity wave seeding is compelling because high occurrences of irregularities correlate with high occurrences of OLRs in the South American, African, and West Pacific sectors during solstices, and low occurrences of OLRs correspond to low irregularities at the East Pacific sector. Our finding is the same with Tsunoda's for the South American and African sectors, but the result of 
good correlation has been extended year long. On the other hand, we found no correlation for the West Pacific and East Pacific sectors when the data is studied for every season (month). As the current study is to see if the gravity wave can serve as seeds of the RT instability globally at every longitude sector year long, the condition of gravity wave seeding becomes more stringent than what has been studied by Tsunoda (2010a,c). With a better data availability and resolution in the $\mathrm{m} / \mathrm{l}$ distributions of irregularities and OLRs, we found no correlation between the irregularities and OLRs at five out of seven longitude sectors every month.

The reason for the lack of correlation at so many longitude sectors between the irregularities and OLRs, in our opinion, is due to the fact that the former is an electrodynamic phenomenon that occurs near the magnetic equator, while the latter is a meteorological phenomenon that appears around the geographic equator and migrates across the equator with season. Since the magnetic equator is offset with respect to the geographic equator, the two phenomena rarely coincide with each other topographically in the $\mathrm{m} / \mathrm{l}$ distributions at a longitude sector except in the South American sector and to some extent in the African sector. Furthermore, factors that were mentioned before to affect the gravity wave seeding of the RT instability could also result in many no-correlation conclusions in the Indian and West Pacific sectors.

As the gravity wave induced in the ITCZ cannot directly become seeds for the RT instability globally year long, we would think the electrodynamic perturbations in the ion (electron) density and vertical drift velocity in the lower F region to be the seeds of the RT instability. Close relationship of the electrodynamic perturbations with the irregularity occurrences in the post-sunset ionosphere has been discussed by Hysell (2000) and Mendillo et al. (2001). The occurrences of electrodynamic perturbation have further been discussed by Abdu and Brum (2009) as due to changes in the longitudinal/local-time gradients of E-region conductivities caused by the vertical coupling process in the atmosphere-ionosphere system in the low-latitude region. The electrodynamic coupling process comes from the upward propagating atmospheric waves, such as tidal modes, planetary waves, and gravity waves. We would think that large perturbations will occur at locations where the post-sunset pre-reversal enhancements of vertical drift velocity are higher so that the global s/l distributions of irregularity occurrences can be readily explained. As for electrodynamic perturbations to become seeds of an instability process, numerical simulation by Yokoyama (2013) has shown that random electrodynamic perturbations without specific scale size will excite an instability process in the mid-latitude E-F region to result in medium-scale traveling disturbances with a size of 100 to $200 \mathrm{~km}$. Whether a similar process will occur in the equatorial region needs to be studied further. However, evolution of electrodynamic perturbations to become seeds of the RT instability for the equatorial irregularity occurrences seems a definitive possibility. Finally, the relationship between the large-scale wave structure (LSWS) observed as the precursor of irregularity occurrences (Tsunoda 2008; Tsunoda et al. 2011; Li et al. 2012; Tulasi Ram et al. 2014) and the post-sunset density perturbation also needs further examination.

\section{Competing interests}

The authors declare that they have no competing interests.

\section{Authors' contributions}

SYS conceived the idea of the study and is the main author of the paper. CLW is the MS student who plotted the figures and also used some of the contents for the thesis material. CHL is the coauthor who has extensive discussions with SYS about the thought of the seeding mechanism and the rebuttal to the reviewers' comments. All authors read and approved the final manuscript.

\section{Acknowledgements}

The work was supported in part with a grant from the USA AFOSR project AOARD 11-4040 and in part with a grant from the Taiwan project NSC1002111-M-008-010. We also thank the reviewers for critical comments which enhanced the readability of this report.

\section{Author details}

'Center for Space and Remote Sensing Research, National Central University, 300 Chung-Da Road, Chung-Li 320, Taiwan. ${ }^{2}$ Institute of Space Science, National Central University, 300 Chung-Da Road, Chung-Li 320, Taiwan. ${ }^{3}$ Academia Sinica, 128 Academia Road, Section 2, Nankang, Taipei 115, Taiwan.

Received: 4 March 2014 Accepted: 24 September 2014 Published: 6 November 2014

\section{References}

Aarons J (1982) Global morphology of ionospheric scintillation. Proc IEEE 70:360-378

Aarons J (1993) The longitudinal morphology of equatorial F-layer irregularities relevant to their occurrences. Space Sci Rev 63:209-243. doi:10.1007/ BF00750769

Abdu MA, Brum CGM (2009) Electrodynamics of the vertical coupling process in the atmosphere-ionosphere system of the low latitude region. Earth Planets Space 61(4):385-395

Abdu MA, de Medieros RT, Sobral JHL (1982) Equatorial spread F determined from ionogram. Geophys Res Lett 9:692-695. doi:10.1029/GL009i006p00692

Burke WJ, Huang CY, Gentile LC, Bauer L (2004) Seasonal-longitude variability of equatorial plasma bubble occurrence. Ann Geophys 22:3089-3098

Fejer BG, Scherliess L, de Paula ER (1999) Effects of the vertical plasma drift velocity on the generation and evolution of equatorial spread F. J Geophys Res 104:19859. doi:10.1029/1999JA900271

Gentile A, Burke WJ, Rich FJ (2006) A climatology of equatorial plasma bubbles from DMSP 1989-2004. Radio Sci 41:RS5S21. doi:10.1029/2005RS003340

Gu G, Zhang C (2002) Cloud components of the intertropical convergence zone. J Geophys Res 107(D21):4565. doi:10.1029/2002JD002089

Hanson WB, McClure JP, Sterling DL (1973) On the cause of equatorial spread F. J Geophys Res 78:2353-2356. doi:10.1029/JA078i013p02353

Harerendel G (1973) Theory of equatorial spread F. Max-Planck-Inst fur Phys and Astrophys, Garching, Germany (reprint)

Hei MA, Heelis RA, McClure JP (2005) Seasonal and longitudinal variation of large-scale topside equatorial plasma depletions. J Geophys Res 110, A12315. doi:10.1029/2005JA011153

Huang CS, Kelley MC (1996) Nonlinear evolution of equatorial spread F: 1. On the role of plasma instability and spatial resonance associated with gravity wave seeding. J Geophys Res 101:283. doi:10.1029/95JA02211

Huang CS, Kelley MC, Hysell DL (1993) Nonlinear Rayleigh-Taylor instabilities, atmospheric gravity waves and equatorial spread F. J Geophys Res 98:15631. doi:10.1029/93JA00762 
Huang CY, Burke WJ, Machuzak JS, Gentile LC, Sultan PJ (2002) Equatorial plasma bubbles observed by DMSP satellites during a full solar cycle: toward a global climatology. J Geophys Res 107:A12. doi:10.1029/2002JA009398

Huba JD, Joyce G, Krall J (2008) Three-dimensional equatorial spread F modeling. Geophys Res Lett 35:L10102. doi: 10.1029/2008GL033509

Hysell D (2000) An overview and synthesis of plasma irregularities in equatorial spread F. J Atmos Sol Terr Phys 62:1037-1056. doi:1016/\$1364-6826(00) 00095-X

Hysell DL, Burcham JD (1998) JULIA radar studies of equatorial spread F. J Geophys Res 103:29155-29167. doi:10.1029/98JA02655

Hysell DL, Kelley MC, Swartz WE, Woodman RF (1990) Seeding and layering of equatorial spread F by gravity wave. J Geophys Res 95:17253-17260. doi:10.1029/JA095iA10p17253

Kelley MC, McClure JP (1981) Equatorial spread-F: a review of recent experimental results. J Atmos Terr Phys 43:427-435

Kelley MC, Pfaff R, Baker KD, Ulwick JC, Livingston R, Rino C, Tsunoda R (1982) Simultaneous rocket probe and radar measurements of equatorial spread F-transitional and short wavelength results. J Geophys Res 87:1575-1588

Keskinen MJ, Ossakow SL, Szuszczewicz EP, Holms JC (1981) Nonlinear theory and experimental observations of the local collisional Rayleigh-Taylor instability in a descending equatorial spread $\mathrm{F}$ ionosphere. J Geophys Res 86:5785-5792

Kil H, Heelis RA (1998) Equatorial density irregularity structures at intermediate scales and their temporal evaluations. J Geophys Res 103:3981-3989

Li G, Ning B, Abdu MA, Wan W, Hu L (2012) Precursor signature and evolution of post-sunset equatorial spread-F observed over Sanya. J Geophys Res 117 A08321. doi: 10.1029/2012JA017820

Maruyama T, Maturra N (1984) Longitudinal variability of annual changes in activity of equatorial spread $\mathrm{F}$ and plasma bubbles. J Geophys Res 89:10903-10912

McClure JP, Hanson WB, Hoffman JH (1977) Plasma bubbles and irregularities in the equatorial ionosphere. J Geophys Res 82:2650-2656

McClure JP, Singh S, Bamgboye DK, Johnson FS, Kil H (1998) Occurrence of equatorial $\mathrm{F}$ region irregularities: evidence for tropospheric seeding. J Geophys Res 103:29119-29135

Mendillo M, Baumgardner J, Pi X, Sultan P (1992) Onset condition for equatorial spread F. J Geophys Res 97:13865-13876

Mendillo M, Meriwether J, Biondi M (2001) Testing the thermospheric neutral wind suppression mechanism for day-to-day variability of equatorial spread F. J Geophys Res 106(A3):3655-3663. doi: 10.1029/2000JA000148

Mukherjee GK, Pragati Sikha R, Parihar N, Rupesh G, Patil PT (2010) Studies of the wind filtering effect of gravity waves observed at Allahabad $\left(25.45^{\circ} \mathrm{N}, 81.85^{\circ}\right.$ E), in India. Earth Planets Space 62(3):309-318

Ossakow SL (1981) Spread-F theories-a review. J Atmos Terr Phys 43:437-452

Park J, Noja M, Stolle C, Luhr H (2013) The ionospheric bubble index deduced from magnetic field and plasma observations onboard Swarm. Earth Planets Space 65(11):1333-1344

Retterer JM (2010) Forecasting low-latitude radio scintillation with 3-D ionospheric plume model: 1. Plume model. J Geophys Res 115, A03306. doi:10.1029/2008JA013839

Rottger J (1981) Equatorial spread F by electric field and atmospheric gravity wave generated by thunderstorms. J Atmos Terr Phys 43:453. doi:1016/0021-9169(81)90108-2

Stolle C, Luhr H, Rother B (2006) Magnetic signature of equatorial spread F as observed by the CHAMP satellite. J Geophys Res 111, A02304. doi:10.1029/2005JA011184

Su SY, Liu CH, Ho HH, Chao CK (2006) Distribution characteristics of density irregularities: equatorial versus midlatitude regions. J Geophys Res 111, A06305. doi: 10.1029/2005JA011330

Sultan PJ (1996) Linear theory and modeling of the Rayleigh-Taylor instability leading to the occurrence of equatorial spread F. J Geophys Res 101:26875-26891

Tsunoda RT (1985) Control of the seasonal and longitudinal occurrence of equatorial scintillations by longitudinal gradient in integrated $\mathrm{E}$ region Pedersen conductivity. J Geophys Res 90:447-456. doi:10.1029/JA090iA01p00447

Tsunoda RT (2008) Satellite traces: an ionogram signature for large-scale wave structure and a precursor for equatorial spread F. Geophys Res Lett 36, L01102. doi:10.1029/2008GL036221

Tsunoda RT (2010a) On seeding equatorial spread F during solstices. Geophys Res Lett 37, L05102. doi:10.1029/2010GL042576
Tsunoda RT (2010b) On seeding equatorial spread F: circular gravity waves. Geophys Res Lett 37, L10104. doi:10.1029/2010GL043422

Tsunoda RT (2010c) On equatorial spread F: establishing a seeding hypothesis. J Geophys Res 115, A12303. doi:10.1029/2010JA015564

Tsunoda RT, Yamamoto M, Tsugawa T, Hoang TL, Tulasi Ram S, Thampi SV, Chau HD, Nagatsuma T (2011) On seeding, large-scale wave structure, equatorial spread F, and scintillation over Vietnam. Geophys Res Lett 38 L20102. doi:10.1029/2011GL049173

Tulasi Ram S, Yamamoto M, Tsunoda RT, Chau HD, Hoang TL, Damtie B, Wassaie M, Yatini CY, Manik T, Tsugawa T (2014) Characteristics of large-scale wave structure observed from African and South Asian longitudinal sectors. J Geophys Res 119. doi:10.1002/2013JA019712

Waliser DE, Gautier C (1993) A satellite derived climatology of the ITCZ. J Clim 6:2162-2172

Waliser DE, Graham NE, Gautier C (1993) Comparison of highly reflective cloud and outgoing longwave radiation datasets for use in estimating tropical deep convection. J Clim 6:331-353

Watanabe S, Oya H (1986) Occurrence characteristics of low latitude ionospheric irregularities observed by impedance probe on board Hinotori satellite. J Geoman Geoelectr 38:125-149

Woodman RF, LaHoz C (1976) Radar observations of F region equatorial irregularities. J Geophys Res 81:5447-5466

Yokoyama T (2013) Scale dependence and frontal formation of nighttime medium-scale traveling ionospheric disturbances. Geophys Res Lett 40:4515-4519. doi:10.1002/grl50905

\section{doi:10.1186/1880-5981-66-134}

Cite this article as: Su et al.: Correlation between the global occurrences of ionospheric irregularities and deep atmospheric convective clouds in the intertropical convergence zone (ITCZ). Earth, Planets and Space 2014 66:134.

\section{Submit your manuscript to a SpringerOpen ${ }^{\odot}$ journal and benefit from:}

- Convenient online submission

- Rigorous peer review

- Immediate publication on acceptance

- Open access: articles freely available online

- High visibility within the field

- Retaining the copyright to your article

Submit your next manuscript at $>$ springeropen.com 